\title{
Problems and prospects of ultra-jet technology in rocket space engineering
}

\author{
(C) V.A. Tarasov, A.L. Galinovskiy
}

Bauman Moscow State Technical University, Moscow, 105005, Russia

The article presents the waterjet technology development and prospects for their improvements based on a number of theoretical and pilot studies.

A special attention is paid to various aspects relating to physical phenomena accompanying the waterjet material processing and also to technological parameters interrelations.

The carried-out experimental and theoretical data analysis has revealed groups of corresponding factors in materials and liquids waterjet processing which enable to make the hypothetical assumption that a number of them has been studied insufficiently and they, with a rather high degree of probability, are perspective for future researches and have an opportunity to become a basis for some new applications of hydrotechnologies.

According to results of numerical modeling by a finite element method main stages related to consecutive development of wave processes in a specified material and on its surface were defined.

The article emphasizes the perspective innovative directions of research developments in the field of hydrotechnologies applications - diagnostics of materials and coatings, microsuspending, disinfecting and activation of hydrotechnological environments, etc.

Keywords: high-speed stream of liquid, material, erosion, suspension, diagnostics, water-jet treatment

Tarasov V.A. (b. 1946) graduated from Bauman Moscow Higher Technical School in 1969. Dr. Sci. (Eng.), Professor, Head of Space-Rocket Engineering Technology Department of Bauman Moscow State Technical University, author of more than 200 scientific papers in the field of mechanical engineering, control and diagnostics. e-mail: tarasov_va@mail.ru

Galinovskiy A.L. (b. 1974) graduated from Bauman Moscow State Technical University in 1999, Dr. Sci. (Eng.), Professor of Space Rocket Engineering Technology Department of Bauman Moscow State Technical University, author of more than 100 scientific papers in the field of mechanical engineering, control and diagnostics. e-mail: galcomputer@mail.ru 